\title{
Cherish Your Exceptions
}

\author{
Frank W. Putnam
}

KEYWORDS. Dissociation, sexual abuse, repressed memory

As the Director of a Child Advocacy Center that evaluated over 1500 children in 2002 for allegations of child abuse or neglect, I have seen many cases enter the Child Protection system. Of these, only a small percentage was ever accepted for criminal prosecution. Those deemed acceptable differ in two major respects from the vast majority of other cases in which allegations of abuse or neglect are sufficiently substantiated to warrant out-of-home placement or other protective interventions. Either the child is able to provide a clear, credible, and consistent account of his/her abuse or there exists convincing supporting evidence, such as a sexually transmitted disease in a non-sexually active child, DNA evidence, serious injuries consistent with the alleged abuse, pornographic pictures of the child, a confession, or credible witnesses. This evidence must strongly point to an identifiable perpetrator(s), and there must be a clear timeline of opportunity and the absence of significant confounds. The average prosecutor prefers to have multiple complementary forms of evidence and is usually quite reluctant to go to trial solely on a child's testimony. Indeed,

Frank W. Putnam, MD, is Professor of Pediatrics and Psychiatry at Cincinnati Children's Hospital, Director of the Mayerson Center for Safe and Healthy Children, Scientific Director of Every Child Succeeds, and Director of the National Child Traumatic Stress Network's Trauma Treatment Replication Center. Formerly Chief of Developmental Traumatology at the National Institute of Mental Health, Dr. Putnam is a nationally recognized expert on the effects of child abuse and neglect.

Address correspondence to: Frank W. Putnam, MD, Mayerson Center for Safe and Healthy Children, ML 3008, Children's Hospital Medical Center, 3333 Burnet Avenue, Cincinnati, OH 45229-3039 (E-mail: frank.putnam@cchmc.org).

Journal of Child Sexual Abuse, Vol. 12(2) 2003

http://www.haworthpress.com/store/product.asp?sku=J070

(C) 2003 by The Haworth Press, Inc. All rights reserved.

10.1300/J070v12n02_10 
I have seen prosecutors rapidly drop cases if a child was unable to consistently describe critical details on subsequent interviews.

Goodman et al. (2003) chose to study a prosecution sample for an understandable reason. The well-documented abuse permitted them to determine if a given disclosed abuse experience was, in fact, the 'target' experience that they were seeking. This strategy addresses a major critique of retrospective studies investigating recall of alleged, but not verified, abuse experiences. By relying solely on a prosecution sample, however, Goodman et al. introduce a major bias that selects against individuals who have difficulty recalling past abuse experiences. In addition, as Freyd (this issue) points out, the rehearsal process involved in preparing children for court (whether or not they actually testify) and the powerful validation of their experiences by the prosecutor (virtually no prosecutor goes to trial unless he/she firmly believes that it happened) act in powerful ways to reinforce recall.

Thus the important finding of this study is not that $81 \%$ of this highly selected sample recalled their target abuse experience, but that $19 \%$ did not-for whatever reason-disclose the target experience. Indeed, every scientific study that has looked for this phenomenon has found that some non-trivial percentage of abused subjects either fails to disclose a targeted abuse experience or reports having 'forgotten' their abuse for a significant period of time. The percentage of such non-disclosing/forgetting subjects varies depending on how the study sample is constructed. Samples of dissociative disorder patients report very high rates of amnesia for childhood abusive experiences, whereas samples such as Goodman et al.'s (2003) have a minority of non-disclosers.

Nonetheless, every study of this phenomenon has documented the existence of a notable percentage of subjects who fail to report their abuse. For example, Sjoberg and Lindblad (2002) had access to seized child pornographic videotapes and thus knew in explicit detail what their sample of children had suffered. Yet most of these children denied or minimized their experiences. In a longitudinal study of an unselected cohort $(N=983)$ followed from birth, investigators found that false negative self-reports of sexual abuse occurred about $50 \%$ of the time (Fergusson, Lynskey, \& Horwood, 1996). These and many other studies demonstrate the reliable finding of a group of non-disclosers of verified child sexual abuse.

For some, the debate turns on whether there exists a special memory mechanism or whether 'normal forgetting' can explain this phenomenon. Goodman et al. (2003), like many skeptics of the existence of amnesia for traumatic experiences, focus on repression as the putative psychological 'mechanism' to be discredited. Nonetheless, being good scientists, they also report that dissociation was significantly correlated with non-disclosure and was a predictor of failure to disclose in the logistic regression analysis. This significance oc- 
curred despite the fact that these analyses used a smaller sample that was "... somewhat biased towards participants who already disclosed abuse" (p. 117).

It is no surprise to clinicians and researchers working with trauma victims that dissociation proved to be predictive of failure to disclose sexual abuse. Dissociation has been strongly linked to trauma in literally hundreds of empirical studies. Dissociation has powerful effects on psychophysiological responses to traumatic reminders and alters cognitive performance on selected tasks of attention and memory. Whether or not one chooses to regard it as a 'special mechanism,' dissociation-not repression-is the psychological process that is likely responsible for at least some of the cases of failure to disclose sexual abuse and other traumas.

The Nobel Prize winning geneticist, George Beadle, used to tell his students, "Cherish your exceptions!" It is good advice for all scientists. In the Goodman et al. (2003) study, the important finding is the group that fails to disclose, despite the fact that so much is biased in favor of disclosure. This group, the exceptions, holds the key to understanding what is happening here. If we can all focus on an objective examination of the empirical evidence, the data will ultimately tell us what this failure to disclose represents.

\section{REFERENCES}

Fergusson, D., Lynskey, M., \& Horwood, L. (1996). Childhood sexual abuse and psychiatric disorder in young adulthood: I. Prevalence of sexual abuse and factors associated with sexual abuse. Journal of the American Academy of Child and Adolescent Psychiatry, 34, 1355-1364.

Freyd, J. J. (2003). Memory for abuse: What can we learn from a prosecution sample? Journal of Child Sexual Abuse, 12(2), 97-103.

Goodman, G. S., Ghetti, S., Quas, J. A., Edelstein, R. S., Alexander, K. W., Redlich, A. D., Cordon, I. M., \& Jones, D. P. H. (2003). A prospective study of memory for child sexual abuse: New findings relevant to the repressed-memory debate. Psychological Science, 14(2), 113-118.

Sjoberg, R., \& Lindblad, F. (2002). Limited disclosure of sexual abuse in children whose experiences were documented on videotape. American Journal of Psychiatry, 159, 312-314. 